2020-06-17

\title{
Ambrein: a minor, but common constituent of mammalian faeces?
}

\author{
Rowland, Steven
}

http://hdl.handle.net/10026.1/15729

10.1080/14786419.2020.1731746

Natural Product Research

Informa UK Limited

All content in PEARL is protected by copyright law. Author manuscripts are made available in accordance with publisher policies. Please cite only the published version using the details provided on the item record or document. In the absence of an open licence (e.g. Creative Commons), permissions for further reuse of content should be sought from the publisher or author. 


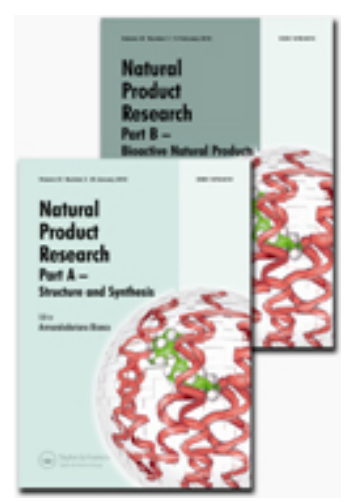

\section{Ambrein: a minor, but common constituent of mammalian faeces?}

\begin{tabular}{|r|l|}
\hline Journal: & Natural Product Research \\
\hline Manuscript ID & Draft \\
\hline Manuscript Type: & Research Article \\
\hline Dute Submitted by the & n/a \\
\hline Complete List of Authors: & $\begin{array}{l}\text { Rowland, Steven; University of Plymouth, } \\
\text { Sutton, Paul; University of Plymouth, School of Geography, Earth \& } \\
\text { Environmental Sciences } \\
\text { von der Leuhe, Barbara; University of Göttingen, Physical Geography } \\
\text { Vane, Christopher; British Geological Survey, Centre for Environmental } \\
\text { Geochemistry } \\
\text { Volkman, John; The Commonwealth Scientific and Industrial Research } \\
\text { Organisation } \\
\text { Ingram, Simon; University of Plymouth, School of Biological and Marine } \\
\text { Sciences } \\
\text { Claridge, Diane; Bahamas Marine Mammal Research Organization, Marsh } \\
\text { Harbour } \\
\text { Dunn, Charlotte; Bahamas Marine Mammal Research Organization, } \\
\text { Marsh Harbour }\end{array}$ \\
\hline Keywords: & \begin{tabular}{l} 
Faeces, Ambrein, Mammals, Humans, Sewage, Sperm whale \\
\hline
\end{tabular} \\
\hline
\end{tabular}

\section{SCHOLARONE ${ }^{\text {IM }}$ Manuscripts}



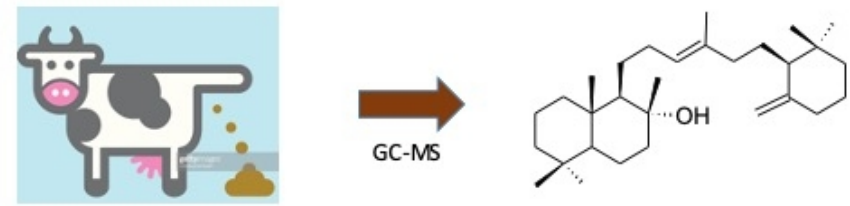


\section{Ambrein: a minor, but common constituent of mammalian faeces?}

Steven J. Rowland ${ }^{1 *}$, Paul A. Sutton ${ }^{1}$, Barbara von der Lühe², John K. Volkman³ ${ }^{3}$ Christopher H. Vane ${ }^{4}$ Simon N. Ingram ${ }^{5}$, Charlotte Dunn ${ }^{6}$, Diane Claridge ${ }^{6}$

1. Biogeochemistry Research Centre, School of Geography, Earth and Environmental Sciences, University of Plymouth, Drake Circus, Plymouth, PL4 8AA, UK.

2. Physical Geography, Institute of Geography, University of Göttingen, Goldschmidtstraße 5, 37077 Göttingen, Germany.

3. CSIRO, Castray Esplanade, Battery Point, Hobart, Tasmania, TAS 7004, Australia.

4. British Geological Survey, Centre for Environmental Geochemistry, Keyworth, Nottingham, NG12 $5 G G, U K$.

5. School of Biological and Marine Sciences, University of Plymouth, Drake Circus, Plymouth, PL4 $8 A A, U K$.

6. Department of Biology, Bahamas Marine Mammal Research Organization, Marsh Harbour, Abaco, Bahamas.

*Corresponding Author: Phone: +44 (0)1752 584557 Fax: +44 (0)1752 584710. E-mail: srowland@plymouth.ac.uk

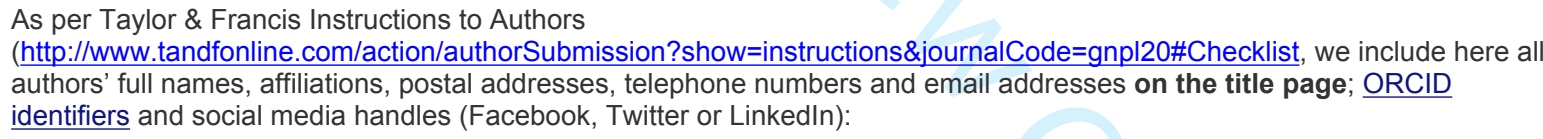

Steven John Rowland, Petroleum and Environmental Geochemistry Group, Biogeochemistry Research Centre, University of Plymouth, Drake Circus, Plymouth, PL4 8AA, UK; +44 (0)1752 584557, srowland@plymouth.ac.uk; ORCID 0000-0003-4980-0618.

Paul Antony Sutton, Petroleum and Environmental Geochemistry Group, Biogeochemistry Research Centre, University of Plymouth, Drake Circus, Plymouth, PL4 8AA, UK; +44 (0)1752 584553; pasutton@plymouth.ac.uk; ORCID 0000-0003-0568-5478.

Barbara von der Lühe,; Physical Geography, Institute of Geography, University of Göttingen, Goldschmidtstraße 5, 37077 Göttingen, Germany.+49 (0)551 39 4570; barbara.von-der-luehe@uni-goettingen.de.

Christopher H. Vane, British Geological Survey, Keyworth, Nottingham, NG12 5GG, UK;+44 (0)115 9363017 ; chv@bgs.ac.uk; ORCID 0000-0002-8150-3640.

Charlotte Dunn, Department of Biology, Bahamas Marine Mammal Research Organization, Marsh Harbour, Abaco, Bahamas; cdunn@bahamaswhales.org.

Diane Claridge, Department of Biology, Bahamas Marine Mammal Research Organization, Marsh Harbour, Abaco, Bahamas; dclaridge@bahamaswhales.org.

Simon N. Ingram, University of Plymouth, Drake Circus, Plymouth, PL4 8AA, UK; +44 (0)1752 584591 ,

simon.ingram@plymouth.ac.uk.

John K Volkman, The Commonwealth Scientific and Industrial Research Organisation, Castray Esplanade, Battery Point, Hobart, TAS 7004, Australia; John.Volkman@csiro.au. 


\begin{abstract}
For nearly 200 years, the only natural source of the alcohol, ambrein, has been coproliths produced in about $1 \%$ of sperm whales and in related jetsam. However, the finding of ambrein in adipocere/faeces of human corpses, led us to hypothesise that ambrein might occur in the faeces of other mammals.

Herein, we used a recently developed gas chromatography-mass spectrometry method, with suitable derivatisation of the hindered hydroxy group of ambrein, to screen a number of extracts of mammalian faeces.

Minor proportions of ambrein were detected in digested human sewage sludge and in the dung of elephant, domestic cattle, giraffe and buffalo, as well as the faeces of a sperm whale. Whether ambrein formation in the terrestrial species is associated with coprolith formation, is unknown, but solid deposits known as enteroliths and fecaliths occur in humans and some domestic animals.
\end{abstract}

Keywords: Faeces, mammals, ambrein, humans, sewage, sperm whale. 


\section{Introduction}

The natural product ambrein (I; Figure 1) was, for nearly two hundred years, known only in ambergris (Pelletier and Caventou 1820 through Rowland et al. 2019), which is a coprolith which occurs in the rectum of about $1 \%$ of sperm whales (Clarke, 2006).

In such coproliths, which can be very large (e.g. 420 kg; Clarke, 1954) and in related jetsam samples, ambrein is usually one of the major components of solvent extracts $(81 \pm 22 \% ; n=43$ for jetsam ambergris; Rowland et al. 2018a).

Determination of the isotopic carbon ratios of ambrein and of co-occurring faecal $5 \beta$-stanols in natural ambergris samples, including in those taken directly from whales, indicated that ambrein was biosynthesised from a different squalene source to that of the sterols (Rowland et al. 2019). Examination of extracts for possible intermediates in biosynthesis suggested a route involving conversion of acyclic squalene to tricyclic ambrein via bicyclics with the polypodane skeleton, presumably by bacteria (Rowland et al. 2019). A wide range of bacteria are certainly indicated by recent studies of the microbiome DNA of whale and jetsam ambergris samples (Macleod et al. 2020).

However, the serendipitous finding of minor proportions of ambrein in human adipocere, which is a waxy substance comprising mainly fatty acid salts formed post-mortem during incomplete anaerobic decomposition of soft tissues, indicates that the natural occurrence of traces of ambrein may be more widespread (von der Lühe et al. 2019). The association with adipocere recovered from the abdominal region of human corpses suggested that perhaps ambrein was produced during the microbial decomposition of human faecal residues. Assuming that the adipocere matrix of saturated fatty acids aided the preservation of ambrein over extended periods of time, von der Lühe et al. (2019) suggested that the association of ambrein with ageing faecal material, preserved under moist oxygen-depleted environments, required more attention in studies of other mammalian samples. Thus, a growing body of evidence suggests that ambrein may be a more common product of mammalian anaerobic bacterial processes then realised previously.

In the present study, we therefore examined the extracts of the faeces of a variety of mammals, including humans, for the presence of ambrein, using recently developed analytical methods (Rowland and Sutton 2017). 


\section{Results and discussion}

Field samples of dung were collected from a variety of terrestrial mammals (elephant, hippopotamus, buffalo, giraffe and domestic cattle) in Mara Conservancy, Narok County, Kenya on 14-17 $7^{\text {th }}$ January 2016 (cf Vane et al. 2010).

A sewage sample was obtained from Göttingen, Germany in November 2018 and freeze-dried in the laboratory.

A sample of faeces was also collected from a sperm whale in south Abaco, Bahamas on September $12^{\text {th }} 2018$ and freeze-dried in the laboratory.

Trimethylsilylated (TMSi) fractions of the dichloromethane extracts of all samples were examined herein by gas chromatography-mass spectrometry (GC-MS) in full data collection (m/z 50-550) or selected ion monitoring (SIM; m/z 143, 203 and 500) modes, or both, using a published method (Rowland and Sutton 2017). Samples of previously authenticated ambrein (Rowland and Sutton 2017) and solvent and procedural blanks, were co-examined.

GC-MS total ion current (TIC) chromatograms of the trimethylsilylated total organic extracts of African mammal faeces revealed several peaks when operating in SIM mode (Figure S1) and intriguingly, one eluted at the same time as the ambrein TMSi ether peak in a derivatised authentic ambergris sample extract (retention time 34.30 minutes). This occurred in all but the sample of hippopotamus faeces extract (MMF4A, Figure S1). However, good quality mass spectra could not be obtained from the data, due to the low amounts present. Therefore, a fractionation procedure was designed in order to provide more concentrated samples from which better mass spectra could be obtained, as follows:

Separation of the buffalo faeces total organic extract MMF7A using adsorption chromatography on silica (method adapted from Rowland et al. 2018b) and elution with $n$-hexane (fraction coded Si F1) followed by $n$-hexane:diethylether ( $1: 1 \mathrm{v} / \mathrm{v}$; fraction $\mathrm{Si} F 2)$, resulted in two fractions. A GC-MS TIC chromatogram (Figure S2) revealed that fraction Si F1 was dominated by odd carbon number $n$-alkanes with 25-35 carbon atoms, whilst fraction Si F2 contained more polar compounds, one of which eluted at the same retention time as the ambrein TMSi ether identified previously in an authentic ambergris sample (34.30 minutes; Figure S2). The mass spectrum of this peak also compared well with the mass spectrum of ambrein TMSi ether from a previously authenticated ambergris extract (Figure S3). SIM GC-MS data were also consistent with the presence of a component assigned to ambrein TMSi ether in the fraction from this 
faeces extract (Figures S4 and S5). The retention index for ambrein TMSi ether on this stationary phase (Agilent DB5 ms; cf Rowland and Sutton 2017 for a different phase), was calculated by comparison with the total ion current chromatogram of the $n$-alkane series.

Similar treatment of all the African mammal extracts produced GC-MS data (Figures S6-S7) indicating that ambrein TMSi ether was present in all the corresponding Si F2 fractions, except the fraction of hippopotamus faeces. SIM GC-MS $(\mathrm{m} / \mathrm{z} 143+203+500)$ of the fractions of derivatised mammalian extracts and an authentic ambergris extract (Figure 1 and Figure S8) supported this conclusion. (Possibly detection in the hippopotamus extract would have required a lower limit of detection in the method).

Following detection of traces of ambrein (as the TMSi ether) in most of the African mammal faeces extracts, a similar investigation was made of extracts of three subsamples of digested human sewage sludge. Total extracts of a freeze-dried sample derivatised with 'Sylon BTZ', were examined by GC-MS in full data collection mode ( $\mathrm{m} / \mathrm{z}$ 50-550). Ambrein TMSi ether was detected in trace amounts relative to the expected faecal steroids, in each of the three subsamples and assigned from the retention positions of authenticated ambrein TMSi ether examined at the same time and from weak mass spectra (notably ions $\mathrm{m} / \mathrm{z} 143$, 175/176/177,192, and 203 were present (Figure S9)). No ambrein was detected in the procedural blank.

Finally, for comparison, a freeze-dried sample of sperm whale faeces excreted from a whale in the Bahamas in September 2018, was extracted and derivatised in the same manner as those of the African mammal samples and human sewage sludge. As expected, ambrein (TMSi ether) was detected and assigned from the retention position of authenticated ambrein TMSi ether examined at the same time, and from the mass spectrum (Figure S10; cf Rowland and Sutton 2107). Again, no ambrein was detected in the procedural blank.

Ambrein has long been recognised to occur in the rare solid coproliths found in a minority of sperm whales (Pelletier and Caventou, 1820; Suzuki 1925; Clarke 1954). In the whales, the nucleating pieces of partially digested squid beaks, the large sizes and the long lives of the whales, probably facilitate accumulation of the large solid boulders (Clarke 1954; 2006). It is therefore perhaps unsurprising that ambrein was also detected herein in the whale faeces. Its presence is presumably a reflection of the action of bacteria in the colon/rectum of the whale (Ueda et al. 2013; Rowland et al. 2019) and its non-detection previously may have been due to use of unsuitable analytical methods. Sperm whale faeces are an important part of the 
'biological pump' of the oceans and have been well studied in respect of the inorganic constituents (Lavery et al. 2010), but less so in terms of the natural organic products (Smith and Whitehead 2000). Also present in the extract (Figure S10), were the two unknown compounds (A1, A2) reported, but not assigned, previously in numerous jetsam ambergris extracts (Rowland and Sutton 2017). Indeed, these are common or ubiquitous in extracts of ambergris derivatised with 'Sylon' (e.g. Rowland et al. 2018b). The mass spectra of the unknowns (Rowland and Sutton 2017) were similar to those reported by Benfenati et al. (1994) for the TMSi-ether derivatives of the enol forms of coprostanone $(5 \beta(\mathrm{H})$-cholestan-3-one). The spectra of the enols herein and previously only differed in having higher abundances of the $\mathrm{M}^{+}, \mathrm{M}-15$ and $\mathrm{M}-29$ ions, which may be due to differences in mass spectrometers used in the different studies. Benfenati et al. reported data for enolisation and derivatisation of both $5 \alpha(H)$ and $5 \beta(H)$ isomers, (viz: cholestanone and coprostanone). These were produced by partial enolization from samples of the pure ketones using bistrimethylsilyltrifluoroacetamide (BSTFA) as a derivatising reagent at $100{ }^{\circ} \mathrm{C}$ for $1 \mathrm{~h}$, whilst further enolization occurred with at room temperature for 24h. Complete enolisation was obtained using $\mathrm{N}$-trimethylsilyl-Nmethyltrifluoroacetamide (MSTFA). This is an example of the capture of the enol form of the ketones as TMSi-derivatives, leading, effectively, to artefactual formation of 3-OH TMSi sterols with $\Delta^{2}$ and/or $\Delta^{3}$ double bonds. The authors could not differentiate between the $\Delta^{2}$ and $\Delta^{3}$, $5 \alpha(\mathrm{H})$ and $5 \beta(\mathrm{H})$ isomers, which had very similar spectra (in contrast to spectra of the corresponding acetates (Autier et al. 1963)). Benfenati et al. conducted ring A deuterium labelling experiments which supported the proposed identifications and particularly showed that the $\mathrm{m} / \mathrm{z} 143$ ion in the mass spectra resulted from fragmentation of the derivatised, enolised $\mathrm{A}$ ring. The elemental composition of this ion, also postulated by Rowland and Sutton (2017) for the spectrum of ambrein-TMSi ether, was confirmed by accurate mass studies (Borges et al. 2005). Benfenati et al. (1994) reported that derivatisation of the $\Delta^{2}$ and/or $\Delta^{3} 5 \beta(H)$ isomers produced a compound which eluted before the corresponding ketone, whereas derivatisation of the $\Delta^{2}$ and/or $\Delta^{3} 5 \alpha(H)$ isomer produced a compound which eluted after the corresponding ketone.

Thus, it is now clear from a comparison of the retention indices of the unknowns in the ambergris extracts (Rowland and Sutton 2017, Rowland et al. 2018 a, b) and in the whale faeces studied herein, with the data of Benfenati et al. (1994), that the unknowns in the derivatised ambergris and faeces extracts are enols of coprostanone. Given the known relative retention times of the TMSi ethers of $\Delta^{4}, \Delta^{5}, \Delta^{6}, \Delta^{8}$ and $\Delta^{7}$ cholestenols (Gerst et al. 1997), it is likely that the first-eluting unknown is the $\Delta^{2}$ and the second the $\Delta^{3} 5 \beta(H)$ isomer. Indeed, after complete derivatization of coprostanone using MSTFA, Chou and Liu (2004) obtained a 
chromatogram with two peaks (1:10 ratio in abundance) with similar spectra to each other (i.e. spectra with $\mathrm{m} / \mathrm{z} 458$ and $\mathrm{m} / \mathrm{z} 143$ ions) which they also attributed to cholest-2-en-5 $\beta$-ol TMSi ether and the $\Delta^{3}$ isomer. Coprostanone (for which the presence of the unknowns now provides evidence) is a well-known intermediate in the formation of coprostanol from cholesterol. The presence of enol forms of coprostanone in derivatised extracts of ambergris, are also consistent with the evidence of carbonyl compounds detected by infrared spectroscopy before derivatisation (Rowland and Sutton 2017; Rowland et al. 2018b).

The finding of ambrein as a major component of extracts of the faeces of the sperm whale is somewhat expected (although unreported previously, to our knowledge). The discovery of traces of ambrein in the faeces of other mammals is more surprising, but there has long been a suggestion that, at least the smell of ambergris, can develop in human faeces. Thus, Beale (1839), cited Brande (1819) as saying "Mr. Homberg found that a vessel in which he had made a long digestion of human faeces, acquired a very strong and perfect smell of ambergris, inasmuch that any one would have thought that a great quantity of essence of ambergris had been made in it, the perfume was so strong and offensive that the vessel had to be removed from the laboratory!". This last phrase was repeated in 1855 by Piesse, who cited Homberg's publications in Mem. Acad. Paris, 1711 and certainly Homberg published at that time on a ' .... suite des observations sur la matiere fecale'. The finding herein, of traces of ambrein in human sewage sludge might be an explanation for these very early physical observations. This is also consistent with the recent report of traces of ambrein in the adipocere of human corpses, perhaps contaminated with faecal matter (von der Lühe et al. 2019). It is unlikely that the ambrein in the sewage is a result of the very minor amounts of ambrein used in perfumes, but this cannot be entirely excluded.

What is without any precedent, as far as we are aware, is the report herein of traces of ambrein in a range of other mammal faeces, including that of giraffe, elephant, domestic cattle and buffalo. These data suggest that ambrein, which is likely a product of bacterial metabolism from squalene (Mori and Tamura 1990; Ueda et al 2013; Rowland et al. 2019), is a more common constituent of mammalian faeces than recognised previously. Indeed, ambrein may now be a useful additional chemical marker of recently deposited faecal material (cf McCalley et al. 1981; Leeming et al. 1996), if it has sufficient chemical longevity in the environment. It is known to survive in the sea, at least in solid coproliths, for at least 1000 years (Rowland et al. 2018a).

\section{Conclusions}

Use of a recently developed gas chromatography-mass spectrometry method, with suitable derivatisation of the hindered hydroxy group of ambrein, to screen a number of extracts of 
mammalian faeces, revealed minor proportions of ambrein in the faeces of humans (digested sewage sludge), elephant, domestic cattle, giraffe and buffalo. These data suggest that ambrein, is a more common, though perhaps minor, constituent of mammalian faeces, than hitherto recognised. Whether ambrein formation in the terrestrial species is associated with coprolith formation, is unknown, but solid deposits known as enteroliths and fecaliths occur in humans and some domestic animals.

Acknowledgements We are grateful to Dr A. Kim (British Geological Survey) for effecting an introduction to $\mathrm{Dr}$ C. H. Vane.

\section{References}

Autier H. Fétizan. Vetter W. 1963. Orientation de la fragmentation en spectrométrie de masse par l'introduction de groupes fonctionnels. 1re partie: $\Delta^{2}$ stéroïdes, tèrpenes et substances apparentées. Bull Soc Chim France 8-9:1971-1974.

Beale T. 1839. The Natural History of the Sperm Whale, John Van Voorst, London, Chapter X.

Benfenati E. Cools E. Fattore E. Fanelli R. 1994. A GC-MS method for the analysis of fecal and plant sterols in sediment samples. Chemosphere 29:1393-1405.

Borges CR. Taccogno J. Crouch DJ. Le L. Truong TN. 2005. Structure and mechanism of formation of an important ion in doping control. Internat J Mass Spec. 247: 48-54.

Brande W.T. 1819. Manual of Chemistry, JW Parker, London.

Chou C-C. Liu Y-P. 2004. Determination of fecal sterols in the sediments of different wastewater outputs by GC-MS. Internat J Environ Analyt Chem. 84:379-388.

Clarke R. 1954. A great haul of ambergris. Nature 174:155-156.

Clarke R. 2006. The origin of ambergris. LAJAM. 5:7-21.

Gerst N. Ruan B. Pang J. Wilson WK. Schroepfer GJ Jr. 1997. An updated look at the analysis of unsaturated $\mathrm{C}_{27}$ sterols by gas chromatography and mass spectrometry. J Lipid Res 38:1685-1701.

Homberg G. 1711. Phosphore nouveau, ou suite des observations sur la matiere fecale. Histoire de l'Académie Royale des Sciences 234-240.

Lavery TJ. Roudnew B. Gill P. Seymour J. Seuront L et al. 2010. Iron defecation by sperm whales stimulates carbon export in the Southern Ocean. Proc R Soc B 277:3527-3531.

Leeming R. Ball. A. Ashbolt N. Nichols P. 1996. Using faecal sterols from humans and animals to distinguish faecal pollution in receiving waters. Water Res. 30:2893-2900.

Macleod R. Sinding M-HS. Olsen MT. Collins MJ. Rowland SJ. 2020. DNA Preserved in Jetsam Whale Ambergris. Roy Soc Biol Lett (in press). 
McCalley DV. Cooke M. Nickless G. 1981. Effect of sewage treatment on faecal sterols. Water Res. 15:1019-1025.

Mori K. Tamura H. 1990. Triterpenoid total synthesis I. Synthesis of . and Ambrox®. Liebigs Ann Chem 361-368.

Pelletier PJ. Caventou JB. 1820. Sur la nature de la substance adipocireuse de l'ambregris et sur l'origine de ce produit. J Pharm. 6:49.

Piesse, S. 1855. On perfumery: perfumes of animal origin. Am J Pharmacy 27:74-75.

Rowland SJ. Sutton PA. 2017. Chromatographic and spectral studies of jetsam and archived ambergris. Nat Prod Res. 15:1752-1757.

Rowland S. Sutton P. Knowles T. 2018a. The age of ambergris. Nat Prod Res 33:3134-3142.

Rowland SJ. Sutton PA. Payne 2018b. Simulated environmental photo- and auto-oxidation of ambrein. Earth ArXiv Pre-print doi: 10.31223/osf.io/x8d4e. Available at https://eartharxiv.org.

Rowland SJ. Sutton PA. Wolff GA. 2019. Biosynthesis of ambrein in ambergris: evidence from isotopic data and identification of possible intermediates. Nat Prod Res. 1-7. doi:10.1080/14786419.2019.1644630.

Smith SC. Whitehead H. 2000. The diet of Galapagos sperm whales Physeter macrocephalus as indicated by fecal sample analysis. Mar Mammal Sci. 16:315-325.

Suzuki 1925. Uber die Natur der Ambra und ihoe Bestandteile. Jap J Med Sci. 2 Biochem. I: $31-$ 42.

Ueda D. Hoshino T. Sato T. 2013. Cyclisation of squalene from both termini: identification of an onoceroid synthase and enzymatic synthesis of ambrein. J Am Chem Soc 135:18335-18338.

Von der Lühe B. Mayes RB. Thiel V. Dawson LA. Graw M. Rowland SJ. Fieldler S. 2019. First evidence of terrestrial ambrein formation in human adipocere. Sci Rep. 9: Article number: 18370.

Vane CH. Kim AW. McGowan S. Leng MJ. Heaton THE. Coombs P. Kendrick CP. Yang H, Swann GEA. 2010. Sedimentary record of sewage pollution using faecal marker compounds in contrasting peri-urban shallow lakes. Science of the Total Environment 409:345-356. 
Figure 1. I: Structure of ambrein. Partial total ion current (TIC) GC-MS chromatograms of solvent and procedural blanks, an $n$-alkane series and extracted ion chromatograms $(\mathrm{m} / \mathrm{z} 143+203+500)$ of a trimethylsilylated, previously authenticated, ambergris extract (ambergris $G=$ sample 5 of Rowland and Sutton 2017) and of trimethylsilylated fractions from separation of total organic extracts of mammalian faeces samples using silica: MMF-1A Elephant; MMF -4A Hippo; MMF7A Buffalo; MMF-10A Giraffe; MMF-16A Domestic cattle. Component with retention time of 34.28 minutes assigned as ambrein TMSi ether. 


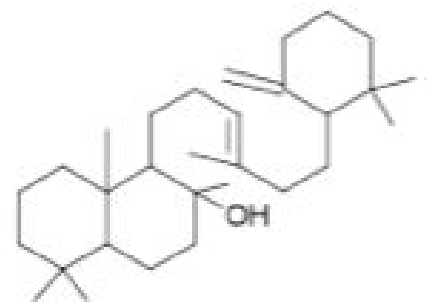

L ambrein

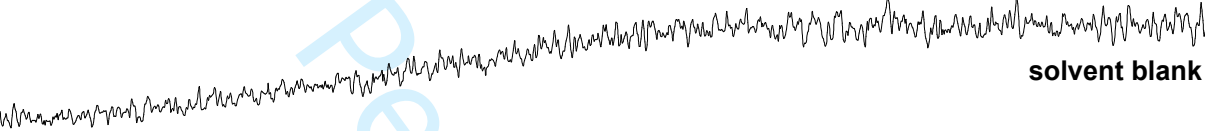

procedural blank Si F1

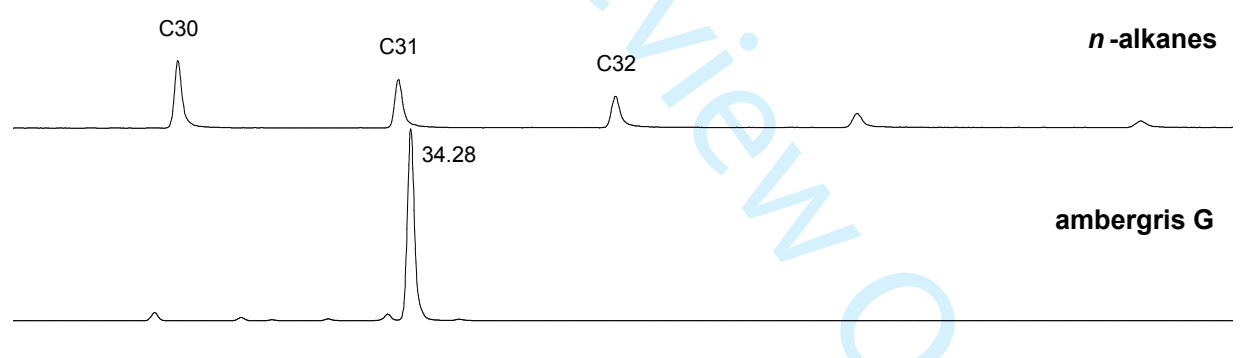

MMF1A Si F1
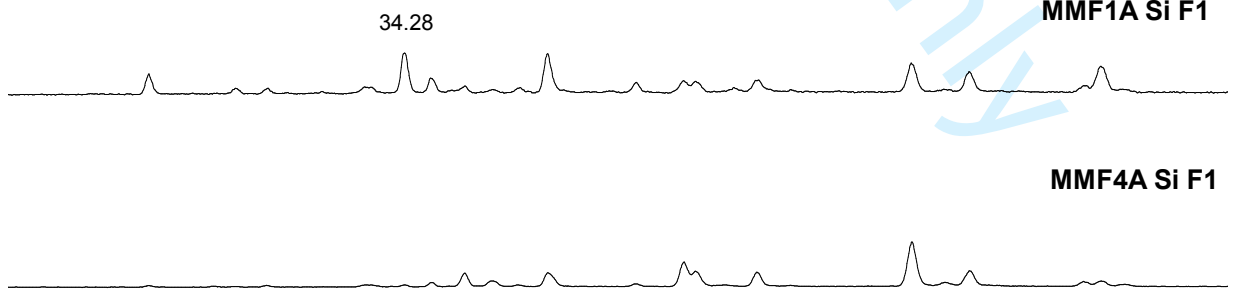

MMF7A Si F1

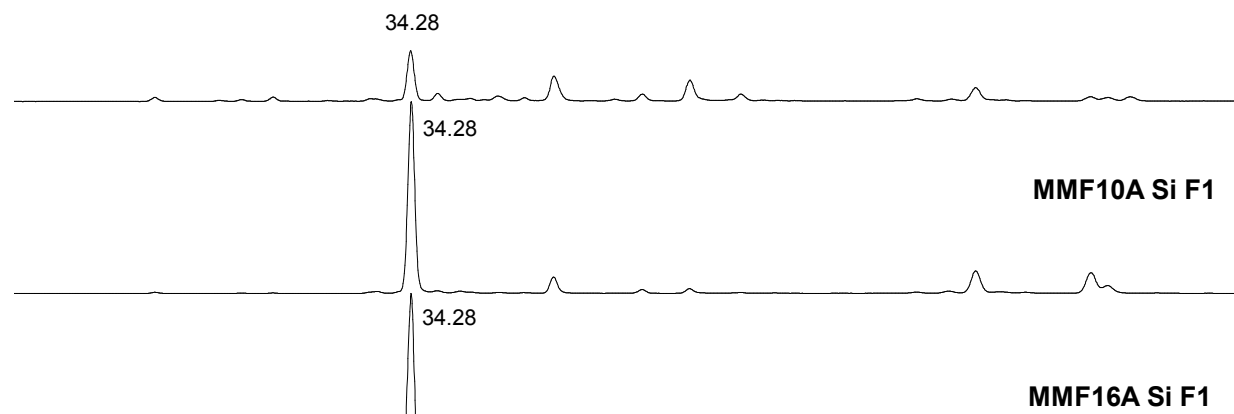

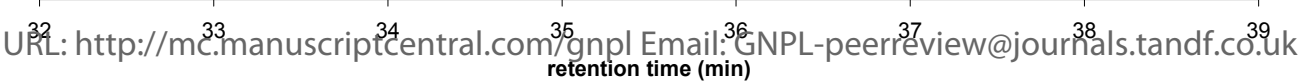




\title{
Ambrein: a minor, but common constituent of mammalian faeces?
}

Steven J. Rowland ${ }^{1 *}$, Paul A. Sutton ${ }^{1}$, Barbara von der Lühe², John K. Volkman ${ }^{3}$, Christopher H. Vane ${ }^{4}$ Simon N. Ingram ${ }^{5}$, Charlotte Dunn ${ }^{6}$, Diane Claridge ${ }^{6}$

1. Biogeochemistry Research Centre, School of Geography, Earth and Environmental Sciences, University of Plymouth, Drake Circus, Plymouth, PL4 8AA, UK.

2. Physical Geography, Institute of Geography, University of Göttingen, Goldschmidtstraße 5, 37077 Göttingen, Germany.

3. CSIRO, Castray Esplanade, Battery Point, TAS 7004, Australia.

4. British Geological Survey, Centre for Environmental Geochemistry, Keyworth, Nottingham, NG12 5GG, UK.

5. School of Biological and Marine Sciences, University of Plymouth, Drake Circus, Plymouth, PL4 8AA, UK.

6. Department of Biology, Bahamas Marine Mammal Research Organization, Marsh Harbour, Abaco, Bahamas.

${ }^{*}$ Corresponding Author: Phone: +44 (0)1752 584557 Fax: +44 (0)1752 584710

E-mail: srowland@plymouth.ac.uk

\begin{abstract}
For nearly 200 years, the only natural source of the alcohol, ambrein, has been coproliths produced in about $1 \%$ of sperm whales and in related jetsam. However, the finding of ambrein in adipocere/faeces of human corpses, led us to hypothesise that ambrein might occur in the faeces of other mammals.

Herein, we used a recently developed gas chromatography-mass spectrometry method, with suitable derivatisation of the hindered hydroxy group of ambrein, to screen a number of extracts of mammalian faeces.

Minor proportions of ambrein were detected in digested human sewage sludge and in the dung of elephant, domestic cattle, giraffe and buffalo, as well as the faeces of a sperm whale. Whether ambrein formation in the terrestrial species is associated with coprolith formation, is unknown, but solid deposits known as enteroliths and fecaliths occur in humans and some domestic animals.
\end{abstract}

Keywords: Faeces, mammals, ambrein, humans, sewage, sperm whale. 


\section{Sample Collection}

Fresh dung samples (coded MMF-1A Elephant; MMF -4A Hippo; MMF-7A Buffalo; MMF-10A Giraffe; MMF-16A Domestic cattle) were collected 14-17 th January 2016 in the Mara Conservancy, Narok County, Kenya (latitude S 1.452015, longitude E 34.91223). Upon return to the laboratory samples were freeze dried for $72 \mathrm{~h}$ and approximately $30 \mathrm{~g}$ (dry wt) ground to a coarse powder using a blender (De Longhi KG40). All samples were then ground in agate ball mill (Retsch PM400) to pass a $63 \mu \mathrm{m}$ brass sieve.

A fresh sample of sperm whale faeces (coded Pm 18-01; 180912-Pmol), was collected off Abaco, the Bahamas, on $12^{\text {th }}$ September 2018. No preservative was added.

A sample of human sewage was collected from Gottingen, Germany in November 2018.

\section{Extraction of mammal faeces}

Methods: Five samples of dried mammal faeces were weighed out (Table 1) and extracted with dichloromethane (DCM; $2 \times 2 \mathrm{~mL}$ ) with sonication (5 min) and centrifugation (2500 $\mathrm{rpm} / 5 \mathrm{~min}$ ). The liquid phase was filtered through a cotton wool plug in a Pasteur pipette and solvent removed under a gentle stream of nitrogen $\left(\mathrm{N}_{2} / 50^{\circ} \mathrm{C}\right)$ before weighing the extract (Table S1). Extracts were reconstituted in DCM (10 mg mL-1). An aliquot (nom. $10 \mu \mathrm{L}$ ) of each extract was diluted (x5), transferred (nom. $10 \mu \mathrm{L}$ ) to a $\mathrm{GC}$ vial, dried (heater block; $60^{\circ} \mathrm{C}$ ) and derivatised (nom. $50 \mu \mathrm{L}$ SYLON BTZ; $70^{\circ} \mathrm{C} ; 1 \mathrm{~h}$ ), before reconstitution in DCM (1 $\mathrm{mL}$ ) for analysis using GC-MS.

A test separation using silica was undertaken using the extract from sample MMF7A. The dried extract was dissolved in a small volume of $n$-hexane (vortex and sonication) and transferred with washings on to silica gel $(510 \mathrm{mg}$; Davisil, grade 645 , pore size $150 \AA, 60$ 100 mesh; Sigma-Aldrich; packed in a $3 \mathrm{~mL}$ glass tube with bottom frit and top frit added over silica) pre-conditioned with diethyl ether $(6 \mathrm{~mL})$ and $n$-hexane $(6 \mathrm{~mL})$ and eluted with $n$ hexane (4 mL; Si F1), n-hexane/diethyl ether 1:1 (v/v; $4 \mathrm{~mL}$; Si F2) and methanol $(4 \mathrm{~mL}$; Si F3; not analysed). Solvent was removed from Si F1 and Si F2 fractions $\left(\mathrm{N}_{2} / 50^{\circ} \mathrm{C}\right)$ and fractions weighed (Table S1) and reconstituted to $1 \mathrm{mg} \mathrm{mL}^{-1}$ (DCM). An aliquot (nom. 100 $\mu \mathrm{L}$ ) was transferred to a GC vial, dried (heater block; $60^{\circ} \mathrm{C}$ ) and derivatised (nom. $50 \mu \mathrm{L}$ SYLON BTZ; $\left.70^{\circ} \mathrm{C} ; 1 \mathrm{~h}\right)$, before reconstitution in DCM $(1 \mathrm{~mL})$ for analysis using GC-MS (Figures 5 and 6).

\section{Extraction of sewage sludge}

Three sub-samples (each 25-35 mg) of a sample of freeze-dried human sewage sludge from Gottingen, Germany, and a procedural blank, were extracted with dichloromethane (DCM; 2 $\times 2.5 \mathrm{~mL}$ ) with sonication (5 min). The liquid phase was filtered through a cotton wool plug in a Pasteur pipette and solvent removed under a gentle stream of nitrogen $\left(\mathrm{N}_{2} / 50^{\circ} \mathrm{C}\right)$ before weighing the extract (Table S2). Extracts were reconstituted in DCM (10 $\left.\mathrm{mg} \mathrm{mL}^{-1}\right)$. An aliquot (nom. $10 \mu \mathrm{L}$ ) of each extract was diluted (x5), transferred (nom. $10 \mu \mathrm{L}$ ) to a $\mathrm{GC}$ vial, dried (heater block; $60^{\circ} \mathrm{C}$ ) and derivatised (nom. $50 \mu \mathrm{L}$ SYLON BTZ; 70 ${ }^{\circ} \mathrm{C} ; 1 \mathrm{~h}$ ), before reconstitution in DCM $(1 \mathrm{~mL})$ for analysis using GC-MS.

\section{Extraction of sperm whale faeces}

A sample of freeze-dried faeces $(23.2 \mathrm{mg})$ from the whale, along with a procedural blank and sample of previously authenticated ambergris, were extracted with dichloromethane (DCM; 2 $\times 2.5 \mathrm{~mL}$ ) with sonication (5 min). The liquid phase was filtered through a cotton wool plug in a Pasteur pipette and solvent removed under a gentle stream of nitrogen $\left(\mathrm{N}_{2} / 50^{\circ} \mathrm{C}\right)$ before 
weighing the extract $(0.5 \mathrm{mg})$. The extracts were reconstituted in DCM $\left(10 \mathrm{mg} \mathrm{mL}^{-1}\right)$. An aliquot (nom. $10 \mu \mathrm{L}$ ) of each extract was diluted (x5), transferred (nom. $10 \mu \mathrm{L}$ ) to a $\mathrm{GC}$ vial, dried (heater block; $60^{\circ} \mathrm{C}$ ) and derivatised (nom. $50 \mu \mathrm{L}$ SYLON BTZ; $70^{\circ} \mathrm{C} ; 1 \mathrm{~h}$ ), before reconstitution in DCM $(1 \mathrm{~mL})$ for analysis using GC-MS.

GC-MS: A $1 \mu \mathrm{L}$ aliquot of sample was injected split/splitless $\left(250^{\circ} \mathrm{C}\right.$; Agilent $7683 \mathrm{C}$ Series autosampler) onto an Agilent DB-5ms Ultra Inert (30 m x $0.25 \mathrm{~mm} \times 0.25 \mu \mathrm{m})$ column with helium carrier gas (constant flow mode; $\left.1 \mathrm{~mL} \mathrm{~min}^{-1}\right)$. The column was interfaced $\left(280^{\circ} \mathrm{C}\right)$ with an Agilent $5975 \mathrm{C}$ Inert $\mathrm{XL}$ El/CI MSD (ion source $230^{\circ} \mathrm{C}$; MS quad $150^{\circ} \mathrm{C}$ ) and the Agilent $7890 \mathrm{~A} \mathrm{GC}$ oven was programmed from $40-300^{\circ} \mathrm{C}$ at $10^{\circ} \mathrm{C} \mathrm{min}^{-1}$ with a 10 minute isothermal hold period. Mass spectra were recorded from $\mathrm{m} / \mathrm{z} 50-550$ or in selected ion monitoring (SIM) mode (tune optimised on $\mathrm{m} / \mathrm{z} 219$ ) using $\mathrm{m} / \mathrm{z} 143,203$ and 500.

Table S1. Gravimetric data $(\mathrm{mg})$ and percentage recovery in brackets from extraction of mammal faeces (note increased recoveries from ground-up samples).

\begin{tabular}{|l|c|c|c|c|c|}
\hline & MMF1A & MMF4A & MMF7A & MMF10A & MMF16A \\
\hline $\begin{array}{l}\text { Sample } \\
\text { weight }\end{array}$ & 64.7 & 56.1 & 78.8 & 48.1 & 53.8 \\
\hline Extract & $1.4(2 \%)$ & $3.0(5 \%)$ & $7.6(10 \%)$ & $5.2(11 \%)$ & $4.2(8 \%)$ \\
\hline Si F1 & $0.5(0.8 \%)$ & $0.6(1.1 \%)$ & $0.2(0.3 \%)$ & $0.2(0.4 \%)$ & $0.1(0.2 \%)$ \\
\hline Si F2 & $0.3(0.5 \%)$ & $0.6(1.1 \%)$ & $1.2(1.5 \%)$ & $1.0(2.1 \%)$ & $0.7(1.3 \%)$ \\
\hline
\end{tabular}

Table S2. Gravimetric data $(\mathrm{mg})$ and percentage recovery in brackets from extraction of human sewage sludge.

\begin{tabular}{|l|c|c|c|}
\hline & SS1 & SS2 & SS3 \\
\hline $\begin{array}{l}\text { Sample } \\
\text { weight }\end{array}$ & 25.3 & 34.7 & 33.7 \\
\hline Extract & $0.9(4 \%)$ & $<0.1(<1 \%)$ & $0.4(1 \%)$ \\
\hline
\end{tabular}


Figure S1. GC-MS TIC chromatograms of dichloromethane solvent (DCM) and procedural (Sylon BTZ) blanks, a $\mathrm{C}_{25-34}$ n-alkane mixture and selected ion monitoring (SIM) chromatograms $(\mathrm{m} / \mathrm{z} 143+203+500)$ of trimethylsilylated ambergris (ACL454A) and mammal faeces total extracts. A component is present in all mammalian extracts at the retention time of ambrein TMSi ether, which also dominates the chromatogram of the ambergris extract $(A C L$ 454A) at $\sim 34.3$ minutes retention time, except for the extract from hippopotamus (MMF4A). However, good quality mass spectra could not be obtained from data for these total extracts, which were then further fractionated (as des cribbed in the text). 


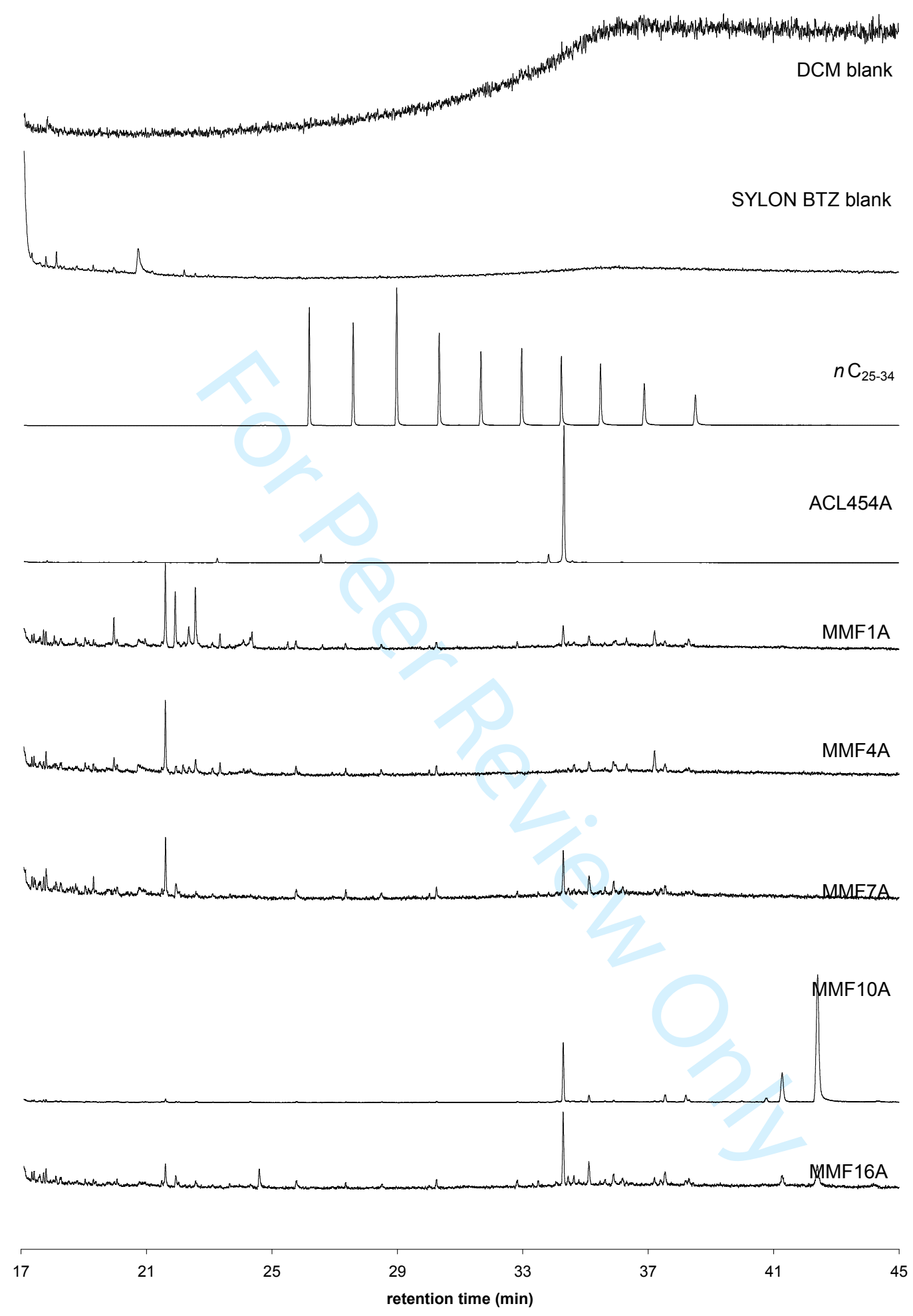


Figure S2. GC-MS TIC chromatograms of blanks and an $n$-alkane mixture and of trimethylsilylated ambergris extract (Ambergris $G$ ) and of trimethylsilylated silica chromatography fractions of a buffalo faeces extract (MMF 7A). Components in fraction F1 of the buffalo faeces extract are $n$-alkanes with carbon numbers as shown. A component is present in fraction Si F2 at the retention time of ambrein TMSi ether. A mass spectrum of reasonable quality mass spectra could be obtained from these data (Figure S3).

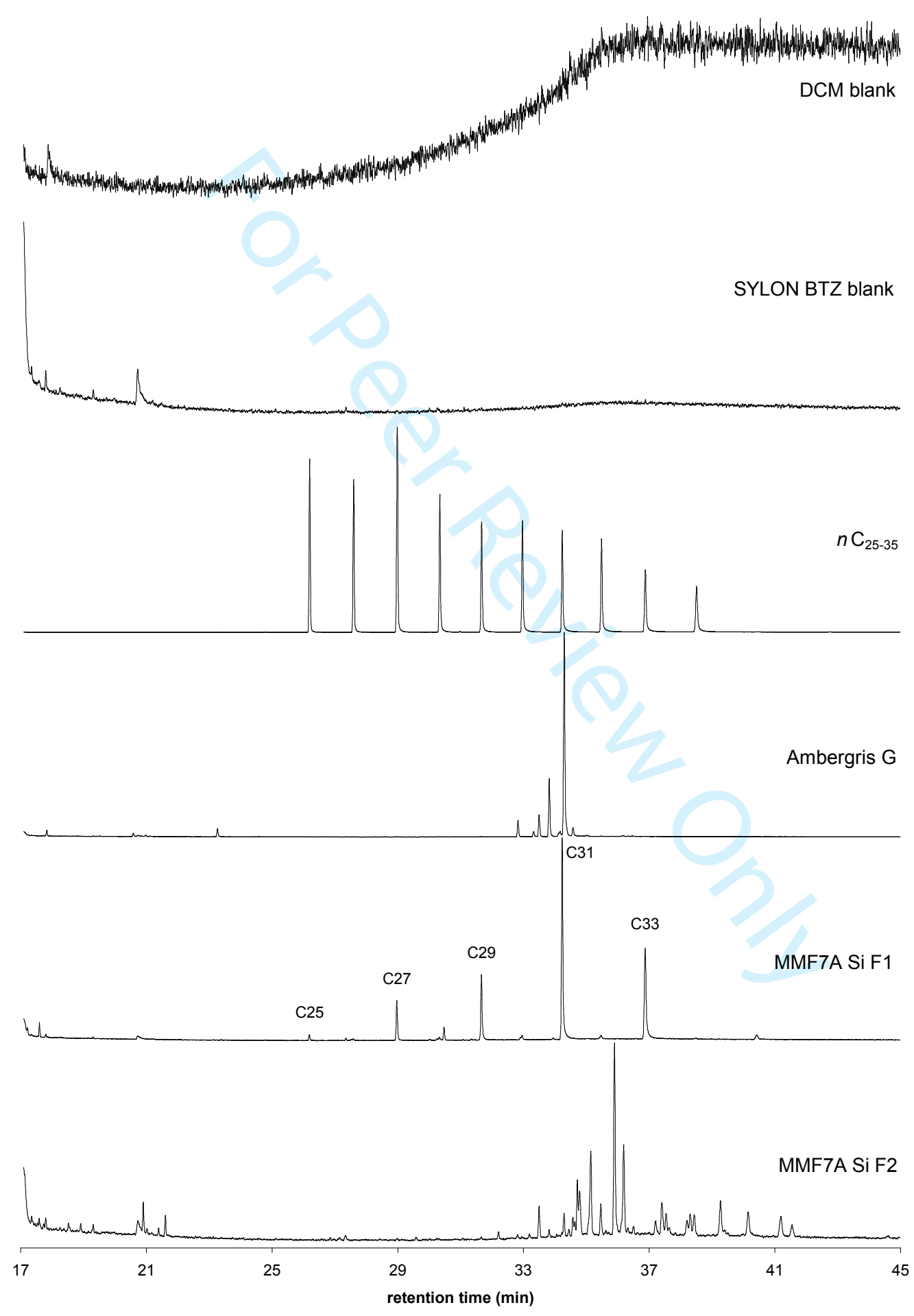


Figure S3. Mass spectra of peaks at 34.30 minutes in GC-MS TIC chromatogram of trimethylsilylated fraction Si F2 of extract of buffalo faeces MMF7A (upper) and authenticated ambrein TMSi ether at same scale (lower). lons due to stationary phase background (e.g. $\mathrm{m} / \mathrm{z} 207,281$ ) are present in the upper spectrum, but key ions in spectrum of ambrein TMSi ether (e.g. m/z 143, 175/176/177, 192 and 203) are also present.
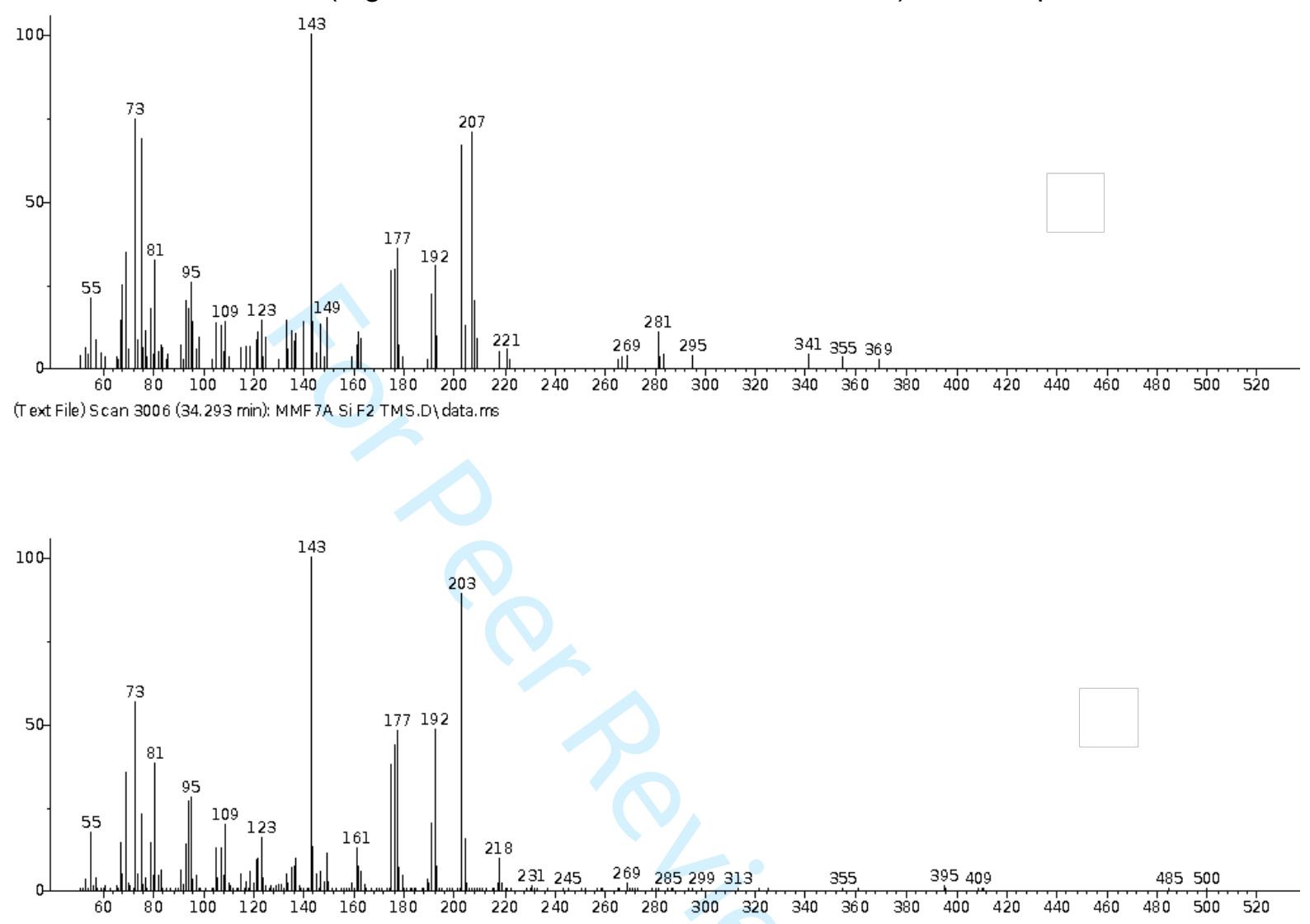
(T ext File) Scan 3007 (34.299 min): Ambergris G TMS.D data.ms 
Figure S4. GC-MS TIC chromatogram of blanks and an n-alkane mixture and SIM chromatograms $(\mathrm{m} / \mathrm{z} 143+203+500)$ of trimethylsilylated authentic ambrein in ambergris (Ambergris $\mathrm{G}$ ) and silica chromatography fractions (Si F1 and F2) of buffalo faeces extract. A component is present in fraction Si F2 at the retention time of ambrein TMSi ether.
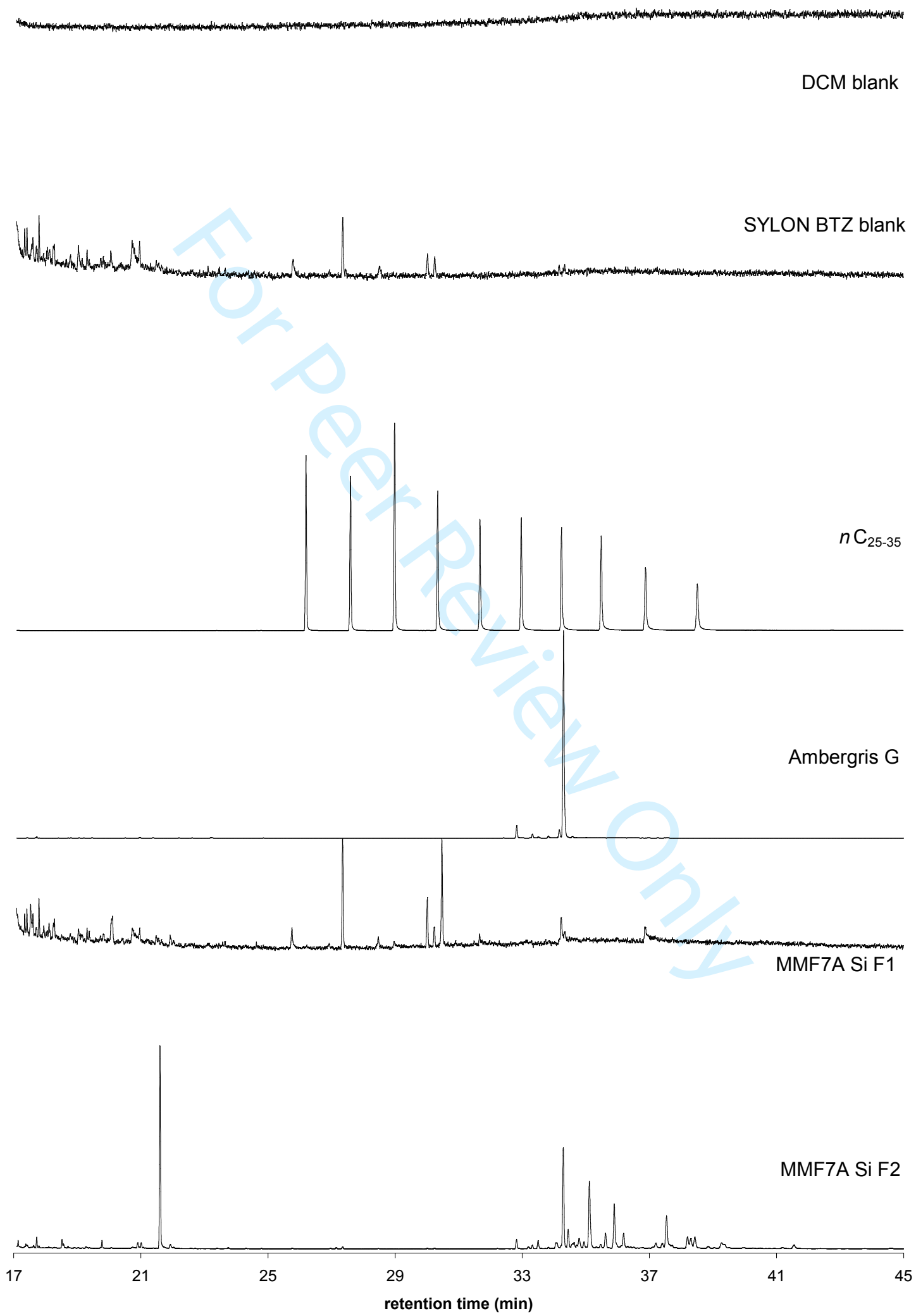
Figure S5. Zoomed (33-37 minutes) GC-MS TIC of blanks and an $n$-alkane mixture and SIM chromatograms $(\mathrm{m} / \mathrm{z} 143+203+500)$ of trimethylsilylated authentic ambrein in ambergris (Ambergris $\mathrm{G}$ ) and silica chromatography fractions (Si F1 and F2) of buffalo faeces extract. A component is present in fraction Si F2 at the retention time (34.3 minutes) of ambrein TMSi ether.

DCM blank
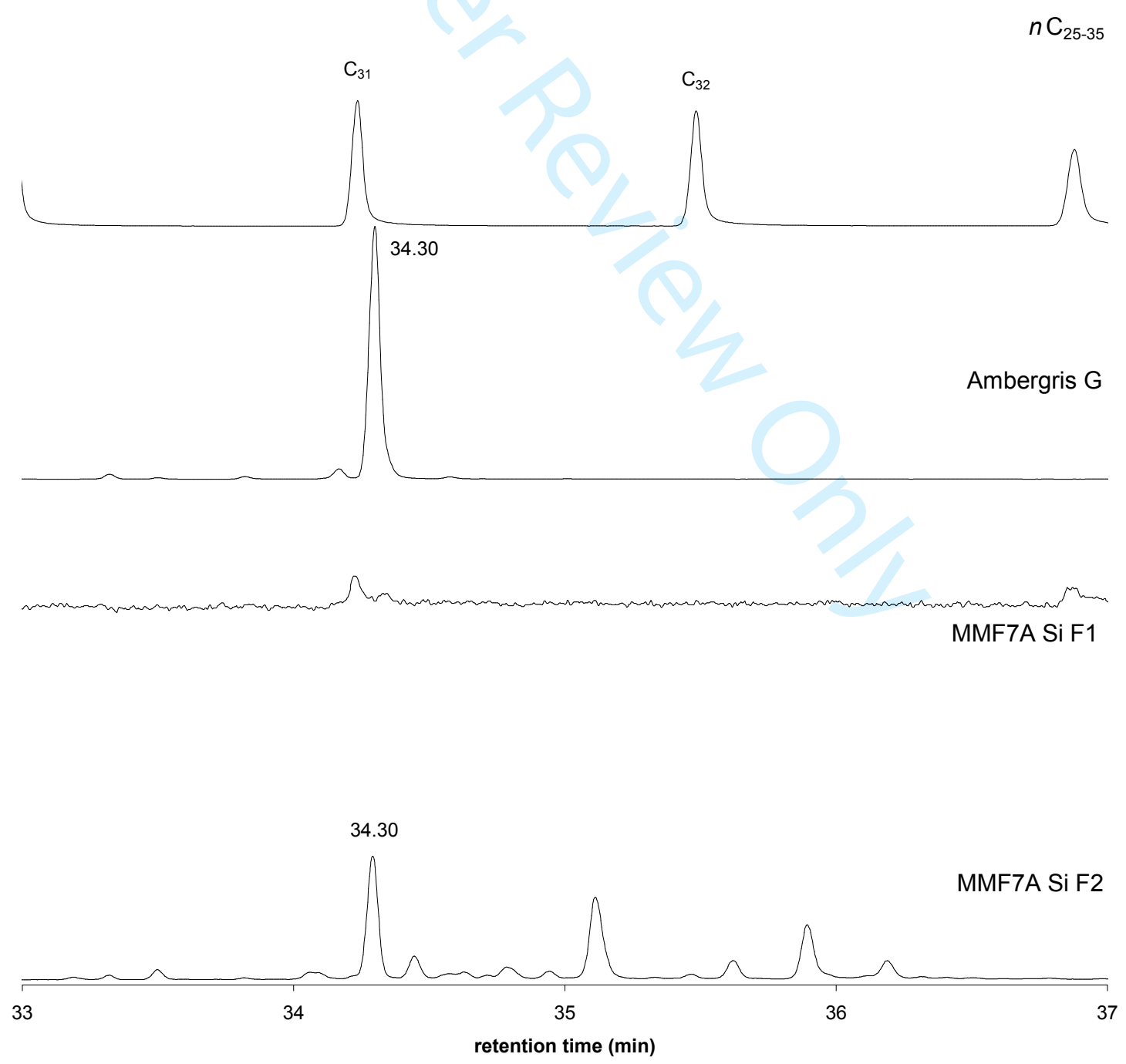
Figure S6. GC-MS total ion chromatograms ( $\mathrm{m} / \mathrm{z}$ 50-550) of blanks, standards and fractions (Si F1) from separation of total organic extract of MMF7A using silica.

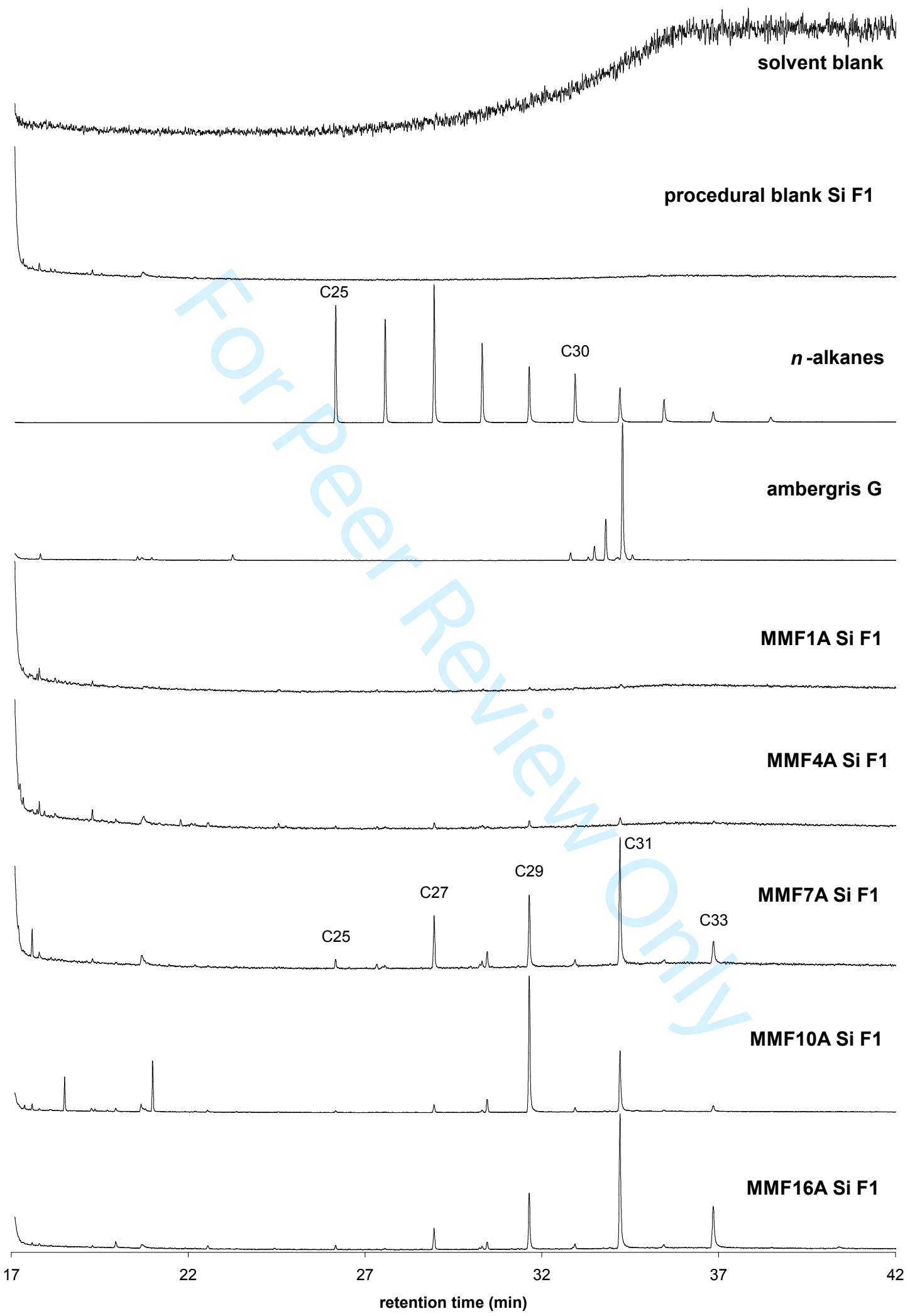


Figure S7. GC-MS TIC ( $\mathrm{m} / \mathrm{z}$ 50-550) of GC-MS total ion chromatograms of blanks, authentic n-alkanes, an ambergris extract (Ambergris $G$ ) and for trimethylsilylated silica chromatography fractions (Si F2) from separation of total organic extracts of African mammalian faeces.

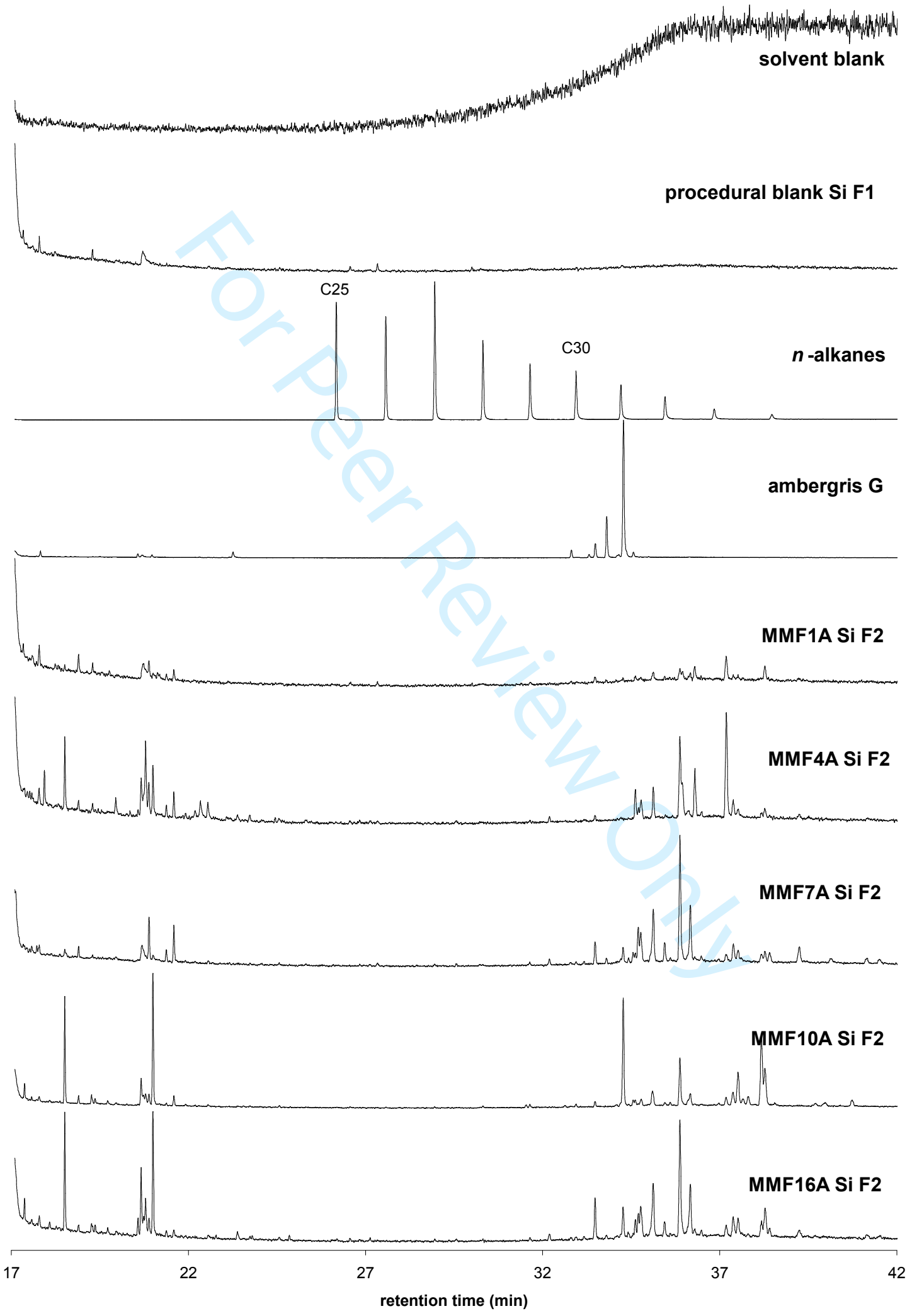


Figure S8. GC-MS total ion chromatograms of blanks, standards and GC-MS SIM $(\mathrm{m} / \mathrm{z} 143$, 203,500 ) data for trimethylsilylated silica chromatography fractions (Si F2) from separation of total organic extracts of African mammalian faeces (zoomed chromatograms are shown in main text Figure 1).
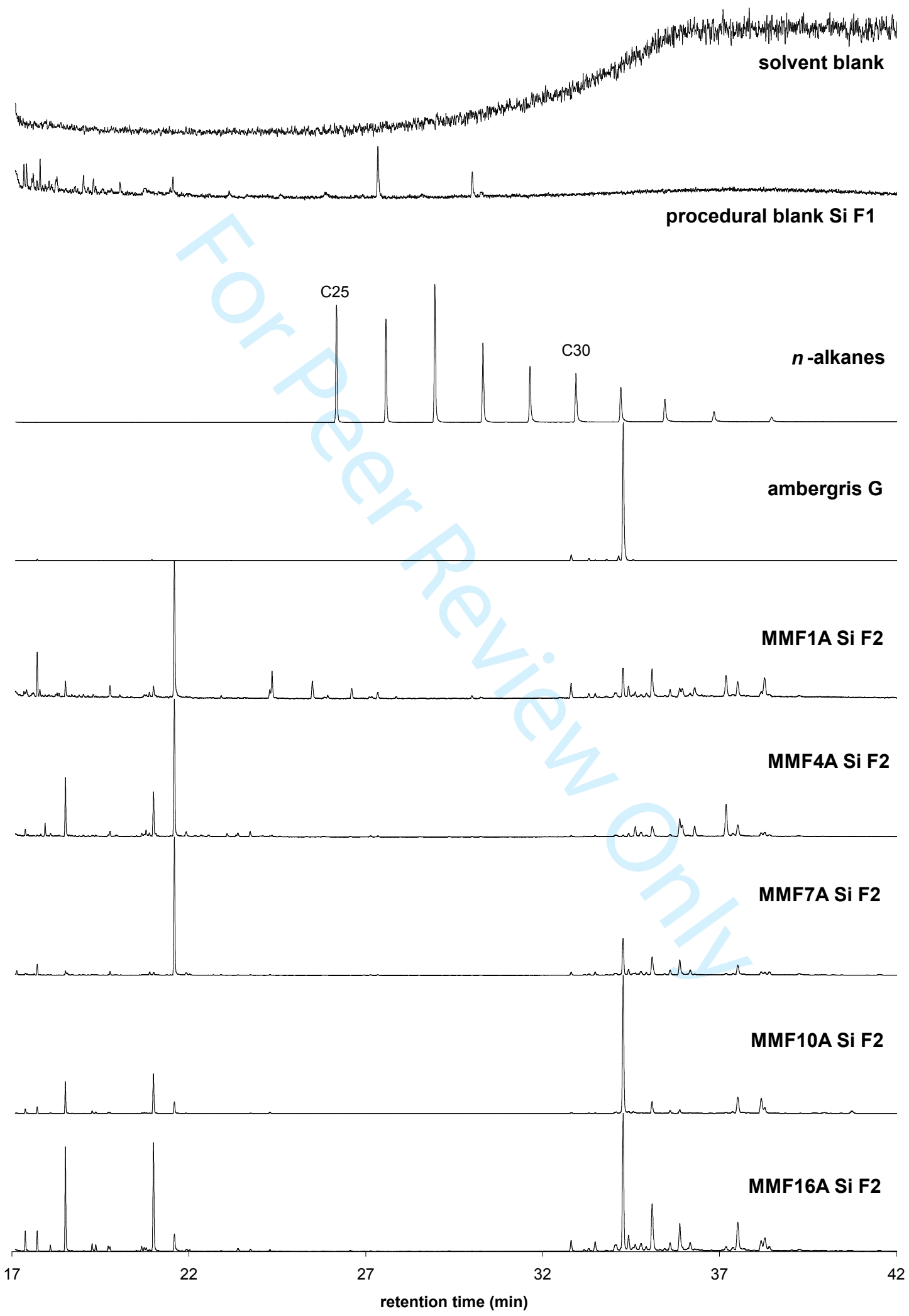
Figure S9. GC-MS total ion current (upper) and (middle) extracted ion chromatograms $(\mathrm{m} / \mathrm{z}$ $143+203+500$ ) of trimethylsilylated total organic extracts of human sewage sludge and (lower) mass spectrum of component assigned as ambrein TMS ether.
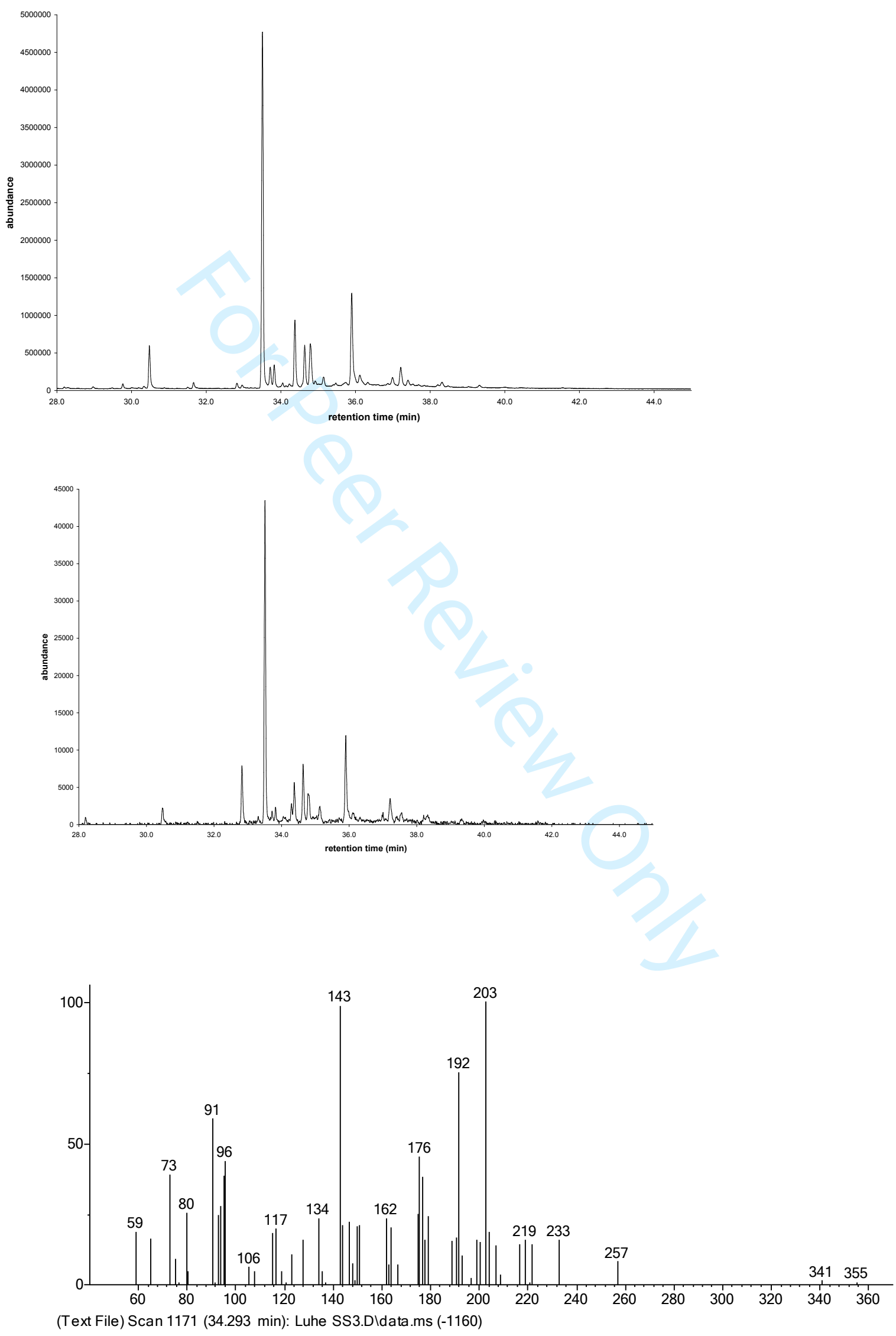
Figure S10. GC-MS total ion current (TIC) chromatogram of trimethylsilylated total organic

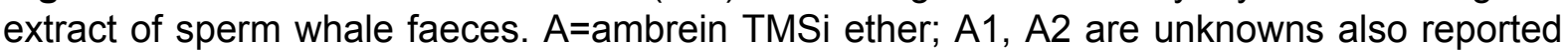
by Rowland and Sutton (2107) in ambergris extracts and now identified herein as TMSi enol ether artifacts of coprostanone derivatisation. Inset shows mass spectrum of component $A$ (ambrein TMSi ether). Other unlabelled (major) peaks in the chromatogram are due to coprostanol and epicoprostanol (TMSi ethers) faecal sterols.

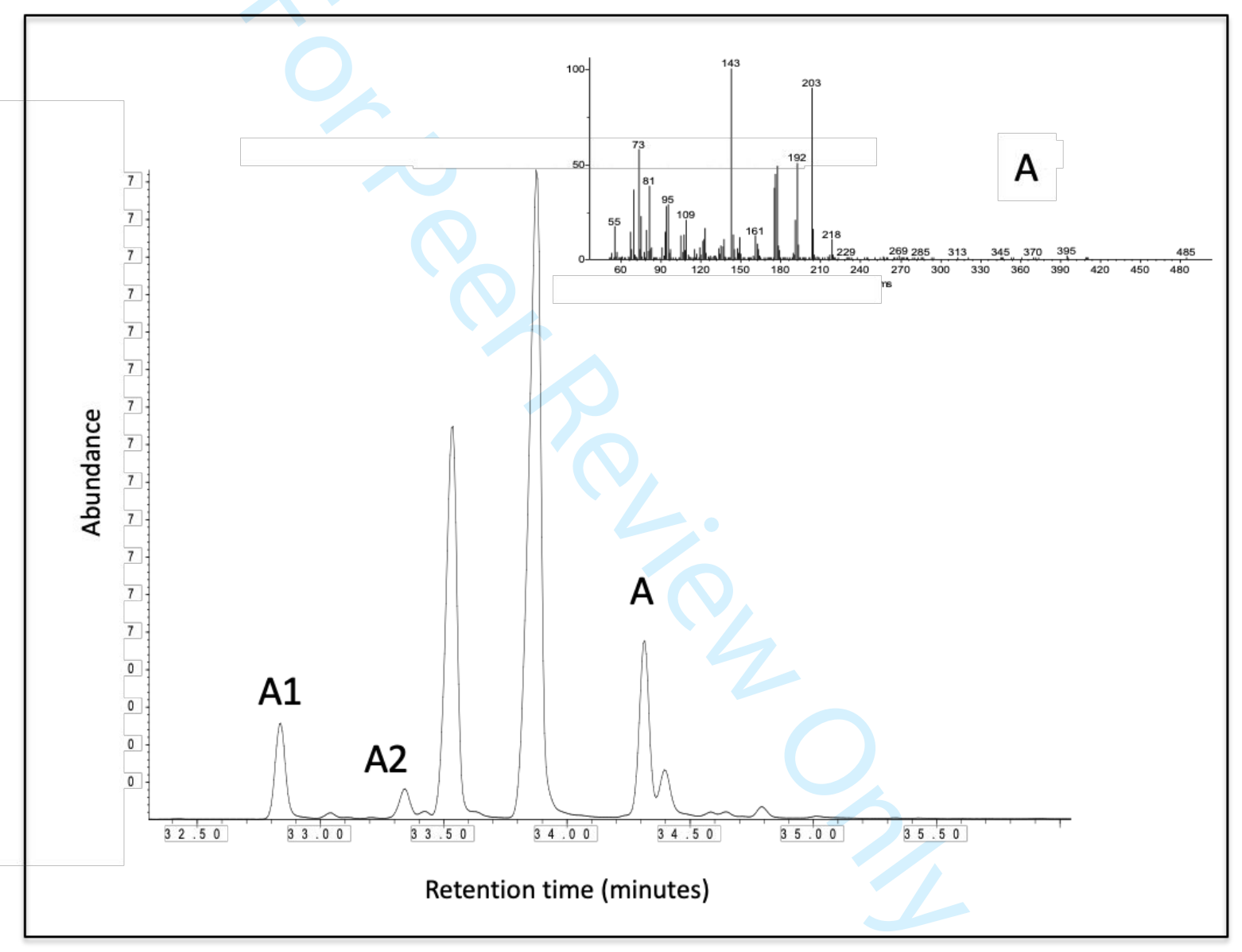

